\title{
Efeitos colaterais do uso da ribavirina, prednisona e DMSO em cães naturalmente infectados pelo vírus da cinomose ${ }^{1}$
}

\author{
Simone H. Mangia ${ }^{2 *}$, Lívia F. Moraes ${ }^{3}$, Regina K. Takahira ${ }^{3}$, Rodrigo G. Motta², \\ Marília M.J. Franco ${ }^{2}$, Jane Megid ${ }^{2}$, Aristeu V. Silva ${ }^{4}$ e Antonio C. Paes ${ }^{2}$
}

\begin{abstract}
Mangia S.H., Moraes L.F., Takahira R.K., Motta R.G., Franco M.M.J., Megid J., Silva A.V. \& Paes A.C. 2014. [The side effects of ribavirin, prednisone and DMSO in dogs naturally infected by canine distemper virus.] Efeitos colaterais do uso da ribavirina, prednisona e DMSO em cães naturalmente infectados pelo vírus da cinomose. Pesquisa Veterinária Brasileira 34(5):449-454. Departamento de Higiene Veterinária e Saúde Pública, Faculdade de Medicina Veterinária e Zootecnia, Universidade Estadual Paulista, Campus Botucatu, Rubião Júnior s/n, Botucatu, SP 18618-970, Brazil. E-mail: simangia@hotmail.com

The present study aims at the identification of undesirable effects of ribavirin, predinisone and DMSO in dogs naturally infected by canine distemper virus. The research analyzed 60 dogs with clinical neurological signs and 10 days of evolution. The animals were hospitalized for the appropriate support treatment; were daily observed, and complete blood cells count, biochemical analysis, and urine exam type I were conducted. Groups 1 and 2 were treated with ribavirin and its combination with DMSO; Groups 3 and 4 treated with prednisone and DMSO, Group 5 treated with ribavirin and prednisone, while Group 6 with ribavirin, prednisone and DMSO. Before the treatment, animals were anesthetized for the cerebrospinal fluid, bone marrow and blood samples collection for the diagnosis based on RT-PCR. The negative samples were analyzed using the hn-PCR technique. All the animals presented positive results in at least one of the 2 tests. The adverse result of ribavirin and its association with prednisone was characterized by haemolytic anemia, confirmed by the evaluation of bilirrubin occurrence only in the urine of dogs treated with ribavirin.
\end{abstract}

INDEX TERMS: Canine distemper, ribavirin, DMSO, prednisone, undesirable effects, dogs.

RESUMO.- 0 estudo tem o objetivo de identificar efeitos indesejáveis da ribavirina, prednisona e DMSO em cães naturalmente infectados com o vírus da cinomose. Foram utilizados 60 cães apresentando quadro neurológico da cinomose com evolução de 10 dias. Os animais foram internados e receberam tratamento de suporte; foram avaliados diariamente e realizados hemograma, dosagem bioquímica e exame de

\footnotetext{
${ }^{1}$ Recebido em 28 de outubro de 2013.

Aceito para publicação em 18 de março de 2014.

${ }^{2}$ Departamento de Higiene Veterinária e Saúde Pública, Faculdade de Medicina Veterinária e Zootecnia (FMVZ), Universidade Estadual Paulista (Unesp), Campus de Botucatu, Caixa Postal 560, Rubião Júnior s/n, Botucatu, SP 18618-970, Brasil. *Autor para correspondência: simangia@ hotmail.com

${ }^{3}$ Departamento de Clínica Veterinária, FMVZ, Unesp-Botucatu, Rubião Júnior s/n, Cx. Postal 560, Botucatu, SP18618-970.

${ }^{4}$ Grupo de Pesquisa em Parasitologia, Laboratório de Análises Clínicas e Parasitologia, Departamento de Ciências Biológicas, Universidade Estadual de Feira de Santana, Av. Transnordestina s/n, Novo Horizonte, Feira de Santana, BA 44036-900, Brasil. E-mail: aristeusilva@gmail.com
}

urina tipo I. Os grupos 1 e 2 foram tratados com ribavirina e sua associação com DMSO; os grupos 3 e 4 com DMSO e prednisona e o grupos 5 com ribavirina e prednisona e o grupo 6 com ribavirina, prednisona e DMSO. Os animais foram anestesiados para a colheita de líquor, medula óssea e sangue, antes do tratamento para diagnóstico através da RT-PCR. As amostras negativas foram analisadas pela técnica de hn-PCR. Todos os animais apresentaram resultado positivo em pelo menos uma das duas reações. 0 efeito adverso da ribavirina e a sua associação com a prednisona foi a anemia hemolítica, que foi confirmada pela observação de bilirrubina na urina apenas dos cães tratados com ribavirina.

TERMOS DE INDEXAÇÃO: Cinomose, ribavirina, prednisona, DMSO, efeitos indesejáveis, caninos.

\section{INTRODUÇÃO}

A cinomose é uma doença viral, causada por um RNA vírus do gênero Morbillivirus, que afeta cães e outros carnívoros em todo o mundo. Mesmo com uso de estratégias vacinais, 
ela ainda é uma doença importante na população canina, apresentando a maior taxa de mortalidade depois da raiva (Summers \& Appel 1994, Greene 2006). A cinomose é ainda uma importante doença e surtos foram recentemente relatados em vários países como Dinamarca, Estados Unidos, Japão, Finlândia e Alemanha (Józwik \& Frymus 2005, Vandevelde \& Zurbriggen 2005). No Brasil, alguns relatos clínico-patológicos e sorológicos indicam a elevada infecção na população canina (Headley \& Graça 2000, Silva et al. 2004). Alguns fatores como a contaminação ambiental e em animais portadores, o aparecimento de novas cepas e o desenvolvimento de infecção e doença mesmo em animais vacinados têm contribuído para a manutenção do caráter enzoótico da virose com ocorrência ocasional de surtos (Böhm et al. 2004).

A ribavirina é uma droga antiviral, análoga à guanosina, inibidora da replicação in vitro de alguns RNA e DNA-vírus, incluindo Herpesvirus, Poxvirus, Influenza vírus, Parainfluenza vírus, Reovirus, Togavirus, Paramyxovirus e Tumor RNA-vírus. "In vivo", o espectro antiviral é restrito, com ação contra Herpesvirus, Influenza, Parainfluenza, Paramyxovirus do Sarampo e Adenovirus (Hayden \& Douglas 1990).

No experimento de Elia et al. (2008) a ribavirina mostrou-se altamente efetiva na prevenção da replicação do vírus da cinomose "in vitro" em baixas concentrações. 0 fármaco é capaz de causar mutações no genoma viral e interfere com a RNA polimerase pela competição com nucleosídeos naturais, produzindo erro na terminação da cadeia do vírus.

Mangia (2008) pela primeira vez usou a ribavirina em cães naturalmente infectados com o vírus da cinomose. Todos os animais apresentavam sinais neurológicos e foram tratados com $30 \mathrm{mg} / \mathrm{kg}$ de ribavirina por via oral, a cada 24 horas, durante 15 dias. Obteve-se melhora clínica nos animais tratados, porém não houve comprovação molecular destes dados. Mangia et al. (2011) demonstraram a eficácia do tratamento com ribavirina na dose de $30 \mathrm{mg} /$ $\mathrm{kg}$, por via oral, a cada 24 horas, durante 15 dias em um caso com encefalite aguda pelo vírus da cinomose, quando associada ao DMSO na dose de $1 \mathrm{~g} / \mathrm{kg}$, por via intravenosa, a cada 24 horas.

A aplicação clínica da ribavirina mostra restrições em humanos devido a alguns efeitos adversos, como a anemia por acúmulo de fosfatos que levam à hemólise (Wu et al. 2005). Os metabólitos fosforilados diminuem os níveis de ATP intracelular, resultando na perda da integridade dos eritrócitos por desestabilização da membrana que pode causar hemólise extravascular (Inoue et al. 2004, Hitomi et al. 2011). A severidade da anemia é mais grave em macacos, a seguir em humanos, roedores e cães (Lin et al. 2003). Ela ocorre em $30 \%$ dos casos tratados e resulta em $9 \%$ a $22 \%$ de pacientes que necessitam a redução da dose para continuar o tratamento. A sua ocorrência está relacionada com a dose, função renal e idade do paciente (Sung et al. 2011).

Sorrells \& Sapolsky (2007) concluíram que, no sistema nervoso, a administração crônica de glicocorticóides ou liberação de corticóide endógeno não são constantemente anti-inflamatórios e em algumas circunstâncias agem au- mentando o processo inflamatório, pelo número de células inflamatórias, pelo nível de mediadores inflamatórios e pela ativação do fator de transcrição. No sistema nervoso lesado, níveis de estresse do glicocorticóide podem induzir uma resposta pró-inflamatória e em níveis basais ou de baixo estresse possuem um efeito tradicional anti-inflamatório.

A solubilização de nucleotídeos em solventes orgânicos é importante para a passagem de fármacos contendo essas substâncias através das membranas celulares. Pelos estudos de West et al. (1994), a base guanosina é hidrofóbica e sua interação com Dimetil-Sulfóxido (DMSO) pode torná-la permeável a substâncias lipofílicas, indicando que este pode servir como veículo de transporte de fármacos nucleotídeas por membranas celulares.

A partir de 1964, o DMSO passou a ser amplamente estudado e utilizado em uma gama imensa de pesquisas científicas pelas quais foram descobertas muitas das suas propriedades farmacológicas, como a captura e remoção de radicais hidróxidos livres, o que explica suas propriedades protetoras como ação anti-inflamatória, anti-isquêmica, crioproteção e radioproteção (Brayton 1986, Paes 1999, Lind et al. 2000, Ali 2001, Kishioka et al. 2007). Este composto contribui para manutenção da microcirculação e reduz a destruição celular pela inflamação. Como mecanismo de ação foi observado que inibe a migração de células inflamatórias, modula a resposta imuno-mediada, inibe a produção de anticorpos e inibe a proliferação de fibroblastos, que pode ser importante nas condições crônicas (Brayton 1986). 0 fármaco é bem tolerado em altas doses, não causa alterações cardíacas e no peso corporal (Ali 2001). Em cães, elevadas doses, podem levar a halitose, anemia, hemoglobinúria e aumento dos níveis de transaminase (Brayton 1986).

O objetivo do estudo foi de identificar efeitos colaterais causados pelo uso de ribavirina, prednisona e DMSO em cães naturalmente infectados com o vírus da cinomose com sinais neurológicos.

\section{MATERIAL E MÉTODOS}

Foram utilizados 60 cães com sinais neurológicos ocasionados pelo vírus da cinomose, diagnosticados a partir do histórico de vacinação, desenvolvimento clínico da doença e exame físico. A confirmação diagnóstica foi realizada pela técnica da reação em cadeia pela polimerase pela transcriptase reversa (RT-PCR), seguida da hemi-nested PCR nos casos negativos.

Para a inclusão dos animais no estudo, os sinais neurológicos deveriam ter apresentação clínica multifocal, ou seja lesões em vários locais do sistema nervoso central, e caráter progressivo de no máximo 10 dias de evolução. Os animais incluídos apresentaram sinais de acometimento dos sistemas respiratório, digestório e ocular simultaneamente ou anterior à apresentação neurológica. Os animais deveriam apresentar entre 2 meses a 6 anos de idade, independente do sexo e raça. Foram divididos de forma aleatória em seis grupos de dez animais quando atendidos no Hospital Veterinário da FMVZ, Unesp-Campus Botucatu, no Serviço de Enfermidades Infecciosas dos Animais:

Grupo 1. Composto por animais tratados com a ribavirina, na dose de $30 \mathrm{mg} / \mathrm{kg}$.

Grupo 2. Composto por animais tratados com ribavirina e DMSO, nas doses de $30 \mathrm{mg} / \mathrm{Kg}$ e $20 \mathrm{mg} / \mathrm{Kg}$ respectivamente. 
Grupo 3. Composto por animais que receberam o DMSO na dose de $50 \mathrm{mg} / \mathrm{kg}$, diluído na concentração de 10 a $20 \%$, por via intravenosa, a cada 24 horas, durante 15 dias.

Grupo 4. Composto por animais que receberam a prednisona na dose de $4 \mathrm{mg} / \mathrm{kg}$, por via oral, a cada 24 horas, durante 7 dias, após receberam $2 \mathrm{mg} / \mathrm{kg}$, por via oral, a cada 24 horas até completar os 15 dias de tratamento. Após este período os animais foram encaminhados para o término do tratamento com glicocorticóide, com redução gradativa da dose.

Grupo 5. Os animais incluídos neste grupo receberam a ribavirina na dose de $30 \mathrm{mg} / \mathrm{kg}$, por via oral, a cada 24 horas, durante 15 dias. Em associação a prednisona foi administrada na dose de $4 \mathrm{mg} / \mathrm{kg}$, por via oral, a cada 24 horas, durante sete dias, com posterior redução da dose para $2 \mathrm{mg} / \mathrm{kg}$, por via oral, a cada 24 horas, até completar o período de 15 dias. Após este período os animais foram encaminhados para o término do tratamento com glicocorticóide, com redução gradativa da dose.

Grupo 6. Composto por cães que receberam $30 \mathrm{mg} / \mathrm{kg}$ de ribavirina, por via oral, a cada 24 horas, durante 15 dias; $50 \mathrm{mg} / \mathrm{kg}$ de DMSO, via intravenosa, a cada 24 horas, durante 15 dias e 0,5mg/ $\mathrm{kg}$ de prednisona, por via oral, a cada 12 horas, durante sete dias, sendo reduzida para $0,25 \mathrm{mg} / \mathrm{kg}$, a cada 24 horas até completar 15 dias de tratamento. Após este período os animais foram encaminhados para o término do tratamento com glicocorticóide, com redução gradativa da dose.

Todos os animais receberam tratamento sintomático e de suporte básico, como antimicrobianos, hidratação, quando em anorexia os animais recebiam glicose intravenosa, complexo B e vitamina $\mathrm{C}$, ácido gama aminobutírico, vitamina $\mathrm{E}$, quando apresentavam lesões oculares foram tratados com pomadas olftálmicas, e foram avaliados neurologicamente todos os dias. Foram realizados exames complementares de forma rotineira. Para tais procedimentos, os animais ficaram internados durante todo o período de tratamento.

A Ribavirina (Ribavirin ${ }^{\circledR}$ ) utilizada na pesquisa possui apresentação de cápsulas de $250 \mathrm{mg}$ e foi diluído para facilitar a administração oral em todos os animais. Foram utilizadas oito cápsulas de ribavirina para $50 \mathrm{~mL}$ de solução fisiológica 0,9\% estéril, formando uma solução de $40 \mathrm{mg} / \mathrm{mL}$. Este fármaco foi utilizado com intervalo de 24 horas na administração e no período de 15 dias em todos os grupos que o receberam.

A prednisona foi adquirida em farmácia de manipulação (Cruz Vermelha, Botucatu, SP), na forma de solução oral, na concentração de $40 \mathrm{mg} / \mathrm{mL}$ em frascos de $50 \mathrm{~mL}$.

O DMSO foi utilizado a sua forma comercial Dimetil Sulfóxido P.A. ${ }^{\circledR}$, na concentração de $99,9 \%$, sendo que para a administração intravenosa, o fármaco foi diluído em solução fisiológica 0,9\% estéril na proporção de 10 a 20\%. Este composto foi utilizado com intervalo de 24 horas e no período de 15 dias em todos os grupos que o receberam.

Foram realizadas duas colheitas de líquor em cada animal sob anestesia, antes e após o tratamento. A técnica de colheita de líquor seguiu a descrição feita por Dewey (2006), onde se utilizou três tubos e a quantidade de líquido colhida variou de 0,5 a $3 \mathrm{~mL}$, dependendo do tamanho do animal. No mesmo momento em que as amostras de líquor foram colhidas, utilizou-se do mesmo procedimento anestésico para a colheita de medula óssea. Este material também foi utilizado para realização do diagnóstico molecular para detecção do vírus da cinomose.

As amostras de sangue foram colhidas no volume de $10 \mathrm{~mL}$, sendo então acondicionados em tubos com EDTA a 7,5\% e sem anticoagulantes. 0 local da punção foi a veia jugular e, após o procedimento, as amostras foram levadas diretamente ao Laboratório Clínico Veterinário para realização de hemograma e análises bioquímicas de função hepática e renal. 0 sistema hepatobiliar foi avaliado a partir da atividade sérica da alanina-aminotransferase (ALT), fosfatase alcalina (FA) e gama-glutamiltransferase (GGT) e da concentração de albumina. 0 sistema renal foi avaliado pela mensuração dos resíduos nitrogenados, ureia e creatinina no soro, e pelo exame de urina tipo I.

Para a realização do exame de urina tipo I foram separados $5 \mathrm{~mL}$ da amostra em tubos e centrifugados na rotação de 1.500 rpm durante cinco minutos, permitindo desta forma, descartar o sobrenadante e o $0,5 \mathrm{~mL}$ restante foi utilizado para confeccionar lâmina para a observação do sedimento urinário em microscópio óptico, em aumento 40x. A outra parte da amostra foi utilizada para o exame físico-químico, sendo o exame físico realizado pela observação de volume, cor e turbidez e a densidade foi obtida por refratometria. Foram utilizadas tiras reagentes para a avaliação de $\mathrm{pH}$, proteínas, glicose, urobilinogênio, presença de bilirrubina e sangue oculto. Para determinação de sais biliares foi utilizado o teste de Hay com sal de enxofre.

Nos animais dos grupos 3 e 4 foi colhido sangue para hemo-

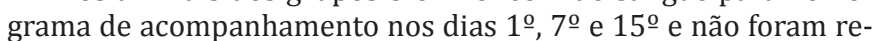
alizados exames bioquímicos. Já nos animais dos grupos 1, 2, 5 e 6 , as amostras de sangue foram colhidas nos dias $1^{\circ} \stackrel{\circ}{ }, 4^{\circ}$, $, 7^{\circ} \stackrel{\circ}{ }, 10^{\circ}$, $12^{\circ}$ e e $15^{\circ}$. As dosagens bioquímicas foram realizadas nos dias $1^{\circ}$, $5^{\circ}, 10^{\circ}$ e $15^{\circ}$.

As amostras de urina foram colhidas preferencialmente pela punção da vesícula urinária e levadas ao mesmo laboratório. No caso de animais muito pequenos foi utilizada a sondagem uretral para obtenção da urina. 0 exame de urina do tipo I foi realizado nos animais dos grupos $1,2,5$ e 6 nos dias $1^{\circ}, 5^{\circ}$,, $10^{\circ}$ e $15^{\circ}$ de tratamento.

A extração do RNA foi realizada nas amostras de sangue, medula óssea e líquor, utilizando-se o Kit para extração de RNA Invisorb $^{\circledR}$ Spin Virus RNA Mini Kit (Inviteck ${ }^{\odot}$ ). Para realização da extração foram diluído $100 \mu \mathrm{L}$ da amostra em $100 \mu \mathrm{L}$ de água livre de nucleases. E para cada cinco amostras foram adicionados um controle negativo que era composto apenas por $200 \mu \mathrm{L}$ de água livre de nucleases. As reações foram realizadas em baterias de 10 amostras por vez. Para controle positivo foi utilizado amostra de urina sabidamente positiva e para realização da extração utilizou-se a mesma diluição em água livre de nucleases.

O RNA foi imediatamente aliquotado em tubos de $7 \mu \mathrm{L}$. Seguido da conversão em cDNA, as amostras $(7 \mu \mathrm{L})$ foram levadas diretamente ao termociclador para desnaturação do RNA, durante sete minutos em temperatura de $95^{\circ} \mathrm{C}$. A mistura para reação foi composta por $3 \mu \mathrm{L}$ de água Mili-Q autoclavada; $1 \mu \mathrm{L}$ de Randon Primer $(250 \eta \mathrm{g} / \mu \mathrm{L}) ; 1 \mu \mathrm{L}$ de dNTP $(10 \mathrm{mM}) ; 5 \mu \mathrm{L}$ de Buffer $5 \mathrm{x} ; 1 \mu \mathrm{L}$ de DDT $(0,1 \mathrm{M}) ; 1 \mu \mathrm{L}$ de inibidor de RNAse $(10 \mathrm{U} / \mu \mathrm{L})$ e $1 \mu \mathrm{L}$ tampão de M-MLV Reverse transcriptase. A mistura formou como volume final $13 \mu \mathrm{L}$. Aliquotou-se $13 \mu \mathrm{L}$ em cada microtubo previamente identificado com o RNA previamente aquecido, totalizando-se $20 \mu \mathrm{L}$. Levou-se ao termociclador no programa CINOCDNA (composto por ciclo de $25^{\circ} \mathrm{C}$ por 10 minutos; $37^{\circ} \mathrm{C}$ por 50 minutos e $70^{\circ} \mathrm{C}$ por 15 minutos, totalizando um período de 1 hora e 15 minutos).

Para a realização da reação de RT-PCR foi necessária a preparação de outra mistura com 17,35 $\mu \mathrm{L}$ de água Mili-Q autoclavada; 2,5 $\mu \mathrm{L}$ de Buffer 10x; 0,75 $\mu \mathrm{L}$ de $\mathrm{Mg}_{2} \mathrm{Cl}_{2}(50 \mathrm{mM}) ; 0,5 \mu \mathrm{L}$ de dNTP $(10 \mathrm{mM}) ; 1,25 \mu \mathrm{L}$ do Primer CDV-NPS F1 (Quadro 1); $1,25 \mu \mathrm{L}$ do Primer CDV-NPS R1 (Quadro 1); 0,15 $\mu \mathrm{L}$ de Taq DNA Platinum $(5 \mathrm{U} / \mu \mathrm{L})$, com volume final de $23,75 \mu \mathrm{L}$ da mistura. Aliquotou-se $23,75 \mu \mathrm{L}$ em cada microtubo previamente identificado, sempre mantido em gelo, na sala de aplicação foi pipetado $1,25 \mu \mathrm{L}$ do cDNA em cada tubo, totalizando $25 \mu \mathrm{L}$ de volume total. Após os microtubos foram levados ao termociclador no programa CINOPCR (composto por ciclo de $95^{\circ} \mathrm{C}$ por 10 minutos, 39 ciclos de $95^{\circ} \mathrm{C}$ por 30 segundos, $5^{6 \circ} \mathrm{C}$ por 30 segundos, $72^{\circ} \mathrm{C}$ por 30 segundos, 
Quadro 1. Descrição da sequência de nucleotídeos iniciadores utilizados na reação de RT-PCR e hn-RT-PCR para a detecção do vírus da cinomose em cães. Botucatu/SP, 2011

\begin{tabular}{lc}
\hline Primers (número de acesso aos genes) & Iniciadores \\
\hline Primer ITS 1 F (10 pmol) & \\
CVD-NPS F1 5'-3' & ATCCCCAGGRAACAAGCCTACAA \\
Primer ITS 1 R (10 pmol) & \\
CVD-NPS R1 5'-3' & CCTTGGTGATGCCAAGCTCG \\
Primer ITS 2 R (10 pmol) & \\
CVD-NPS R2 5'-3' & CGAATTTTAACCCTCCATG \\
\hline
\end{tabular}

Amaral (2007).

depois $72^{\circ} \mathrm{C}$ por 10 minutos e $4^{\circ} \mathrm{C}$ for ever) e, após, foi armazenado a $-20^{\circ} \mathrm{C}$. A leitura do gel foi realizada em gel de agarose a $2 \%$ em transluminador UV, corados em brometo de etídeo, onde se esperou um produto amplificado com $440 \mathrm{pb}$.

Para a reação do hn-PCR, utilizou-se as amostras que foram negativas na RT-PCR, onde aliquotou-se $23,75 \mu \mathrm{L}$ da mistura e $1,25 \mu \mathrm{L}$ do produto amplificado. A mistura foi composta pelos mesmos reagentes, porém na hn-PCR utilizou-se Primer CDV-NPS R2 (Quadro 1) no lugar do Primer CDV-NPS R1, e o produto esperado desta reação apresentou 331pb na leitura do gel. Os iniciadores (primers) utilizados nas duas reações amplificaram regiões específicas do gene da nucleoproteína [GenBank: X02000.1] (Amaral 2007).

A comparação de frequências de ocorrências foi realizada pelos teste de Qui-quadrado ou G de Williams. Para as variáveis ordinais as comparações entre os grupos foi realizada pelo teste de Kruskall-Wallis, seguido de comparação de medianas pelo teste de Dunn. As variáveis discretas e contínuas foram submetidas à verificação do tipo de distribuição pelo teste de Shapiro-Wilkins; quando de distribuição Normal, os grupos foram comparados pela Análise de Variância Um Fator seguido de teste de Tukey; quando de distribuição Livre, os grupos foram comparados pelo teste de Kruskall-Wallis, seguido de comparação de medianas pelo teste de Dunn. Em todas as análises, valores de P menores que 0,05 foram considerados significantes.

0 estudo está de acordo com os Princípios Éticos na Experimentação Animal e foi aprovado pela Câmara de Ética em Experimentação Animal da Faculdade de Medicina Veterinária e Zootecnia, Unesp-Campus Botucatu, no dia 9 de dezembro de 2008, com número de protocolo 222/2008-CEEA.

\section{RESULTADOS}

Todos os animais incluídos na pesquisa foram positivos no diagnóstico molecular para cinomose em pelo menos uma das três amostras colhidas (sangue periférico, medula óssea e/ou líquor).

Todos os grupos apresentaram queda na mediana da contagem de hemácias, evidenciando anemia após o período de tratamento. Os animais dos grupos 3, 5 e 6 apresentaram valores inferiores à 3.500 .000 células/ $\mu \mathrm{L}$ (Quadro 2).

Diferente dos outros grupos, dois animais do G5 e um animal do G6 apresentaram valores da contagem de hemácias abaixo de 2.000 .000 células/ $\mu \mathrm{L}$ no $15^{\circ}$ dia de tratamento, que se pode classificar como anemia intensa.

Não foram encontradas alterações morfológicas em hemácias ou dos índices hematimétricos com significância ao atual estudo.

Após o tratamento experimental, foi possível identificar que a ribavirina em associação com a prednisona levou a queda nos níveis de hemoglobina nos cães dos grupos 5 e 6 diferente do que foi encontrado nos grupos que não receberam a associação dos dois fármacos. Além disso, os grupos 2 e 6 que receberam DMSO em associação aos medicamentos experimentais mantiveram a dosagem de hemoglobina mais elevada do que nos grupos 1 e 5 que usaram os mesmos medicamentos, porém sem o DMSO (Fig.1).

\section{Quadro 2. Mediana e percentis em escores da contagem de hemácias dos cães com cinomose, nos diferentes grupos experimentais, no décimo quinto dia de tratamento.} Botucatu/SP, 2011

\begin{tabular}{lccccc}
\hline Grupo & Mínimo & P25 $^{\mathrm{a}}$ & Mediana & P75 $^{\mathrm{b}}$ & Máximo \\
\hline G1 & 2.560 .000 & 3.177 .500 & 3.895 .000 & 4.835 .000 & 6.180 .000 \\
G2 & 2.743 .000 & 4.550 .000 & 4.710 .000 & 5.012 .500 & 5.362 .318 \\
G3 & 3.340 .000 & 3.408 .000 & 3.480 .000 & 3.905 .000 & 4.730 .000 \\
G4 & 2.050 .000 & 3.310 .000 & 3.860 .000 & 4.192 .500 & 4.800 .000 \\
G5 & 1.320 .000 & 2.367 .500 & 3.080 .000 & 3.832 .500 & 5.490 .000 \\
G6 & 1.870 .000 & 2.760 .000 & 3.400 .000 & 3.595 .000 & 4.180 .000
\end{tabular}

Estatística: Kruskall-Wallis, $p=0,0776 .{ }^{a}$ percentil $25,{ }^{b}$ percentil 75. G1 = grupo 1 (Ribavirina $30 \mathrm{mg} / \mathrm{kg}) ; \mathrm{G} 2$ = grupo 2 (Ribavirina $30 \mathrm{mg} / \mathrm{kg}$ e DMSO 20mg/kg); G5 = grupo 5 (Ribavirina 30mg/kg e Prednisona 4mg/ $\mathrm{kg}$ ); G6 = grupo 6 (Ribavirina $30 \mathrm{mg} / \mathrm{kg}$, Prednisona $2 \mathrm{mg} / \mathrm{kg}$ e DMSO $50 \mathrm{mg} / \mathrm{kg}$ ).

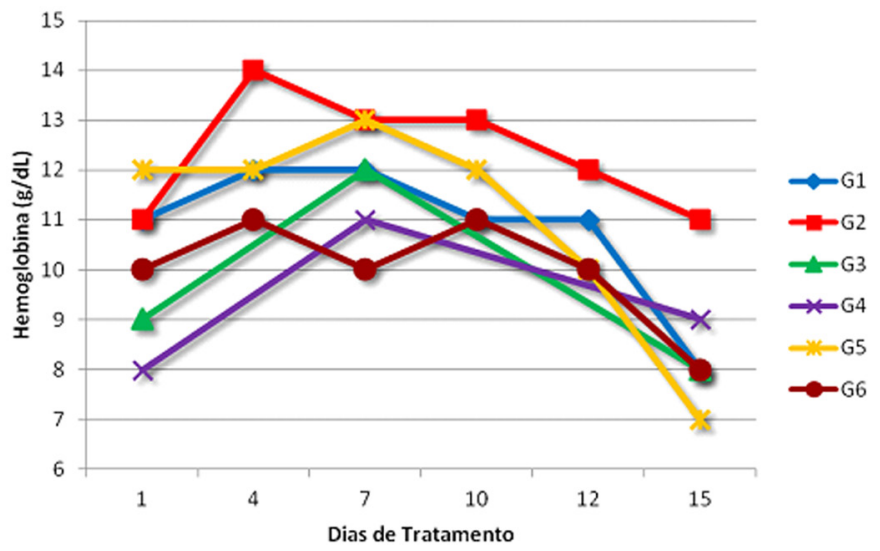

Fig.1. Representação gráfica das medianas da dosagem de hemoglobina dos cães com cinomose, em cada momento de colheita de material nos grupos experimentais. Botucatu/SP, 2011. [Estatística: Teste de Kruskall-Wallis. G1 = grupo 1 (Ribavirina $30 \mathrm{mg} / \mathrm{kg}$ ); $\mathrm{G} 2$ = grupo 2 (Ribavirina 30mg/kg e DMSO 20mg/ kg); G3 = grupo 3 (DMSO 50mg/kg); G4 = grupo 4 (Prednisona $4 \mathrm{mg} / \mathrm{kg}$ ); G5 = grupo 5 (Ribavirina $30 \mathrm{mg} / \mathrm{kg}$ e Prednisona $4 \mathrm{mg} / \mathrm{kg}$ ); G6 = grupo 6 (Ribavirina 30mg/kg, Prednisona $2 \mathrm{mg} / \mathrm{kg}$ e DMSO)]

A contagem de plaquetas e leucócitos não demonstraram alterações relevantes ao estudo.

As dosagens bioquímicas de função hepática e renal não evidenciaram efeitos colaterais dos fármacos experimentais.

0 exame de urina tipo I não apresentou resultado importante com relação às funções hepática e renal. No décimo quinto dia, todos os grupos que receberam a ribavirina apresentaram valores altos da dosagem de bilirrubina na urina, podendo indicar que esta induza anemia por hemólise (Quadro 3). 
Quadro 3. Mediana e percentis em escores da dosagem de bilirrubina na urina dos cães com cinomose, nos diferentes grupos experimentais, no décimo quinto dia de tratamento. Botucatu/SP, 2011

\begin{tabular}{lccccc}
\hline Grupo & Mínimo & P25 & Mediana & P75 & Máximo \\
\hline G1 & 0,0 & 0,0 & 0,0 & 5,0 & 5,0 \\
G2 & 0,0 & 0,0 & 0,0 & 2,0 & 5,0 \\
G5 & 0,0 & 0,0 & 2,5 & 5,0 & 5,0 \\
G6 & 0,0 & 0,0 & 0,5 & 2,0 & 5,0,
\end{tabular}

Estatística: Kruskall-Wallis, p=0,4952. P25 = percentil 25; P75 = percentil 75; $0=$ negativo; $1,0=$ traços de bilirrubina; $2,0=+$ de bilirrubina; $3,0=$ ++ de bilirrubina; 4,0 =+++ de bilirrubina; 5,0 =++++ de bilirrubina. G1 = grupo 1 (Ribavirina 30mg/kg); G2 = grupo 2 (Ribavirina 30mg $/ \mathrm{kg} \mathrm{e}$ DMSO 20mg/kg); G5 = grupo 5 (Ribavirina $30 \mathrm{mg} / \mathrm{kg}$ e Prednisona $4 \mathrm{mg} /$ $\mathrm{kg}$ ); G6 = grupo 6 (Ribavirina $30 \mathrm{mg} / \mathrm{kg}$, Prednisona $2 \mathrm{mg} / \mathrm{kg}$ e DMSO $50 \mathrm{mg} / \mathrm{kg}$ ).

\section{DISCUSSÃO}

A anemia pode ser atribuída ao aumento da destruição dos eritrócitos ou pela diminuição de sua produção. A destruição é determinada pela presença do vírus nos eritrócitos ou pela deposição de imunocomplexos na membrana destas células. A queda da produção pode ser atribuída à falência da medula óssea devido ao estresse desencadeado pela doença. Na maioria dos casos os eritrócitos apresentam-se normocíticos e normocrômicos e não há sinais de regeneração medular (Silva et al. 2005). Concordando com a literatura, a maior parte dos animais da pesquisa apresentava anemia quando chegou para o tratamento, já que todos os grupos tiveram medianas da contagem de hemácias abaixo dos valores de normalidade para cães (Meyer et al. 1995).

Como ocorreu na pesquisa anterior de Mangia (2008), os animais após o período de tratamento com a ribavirina apresentaram valores baixos da contagem de hemácias. No presente estudo verificou-se que todos os grupos apresentaram uma queda na mediana da contagem de hemácias, mesmo os animais do grupo controle. Os animais dos grupos 3, 5 e 6 foram os que apresentaram valores inferiores à 3.500 .000 hemácias/ $\mu \mathrm{L}$. Dois animais do G5 e um do G6 apresentaram valores da contagem de hemácias abaixo de 2.000 .000 células/ $\mu \mathrm{L}$ no $15^{\circ}$ dia de tratamento, que podemos classificar como anemia intensa (Meyer et al. 1995).

A aplicação clínica da ribavirina mostra restrições devido a alguns efeitos adversos, especialmente, indução de anemia hemolítica. 0 acúmulo dos fosfatos do antiviral em eritrócitos leva a anemia (Wu et al. 2005). A severidade da anemia é mais grave em macacos, seguidos dos humanos, roedores e cães (Lin et al. 2003).

No entanto, Papich et al. (2003) afirmam não ter encontrado efeitos colaterais da ribavirina em cães, na dose de 60 $\mathrm{mg} / \mathrm{kg}$ durante duas semanas. No presente estudo, a dose de $30 \mathrm{mg} / \mathrm{kg}$ administrada no período de duas semanas apresentou discreto quadro de anemia, porém quando administrado associado ao glicocorticóide induziu anemia intensa.

Não foram encontrados na literatura relatos de efeitos colaterais da ribavirina potencializados por glicocorticóides, portanto este é o primeiro relato de quadros de anemia severa em cães que receberam ribavirina em associação com a prednisona.
A ribavirina administrada sistemicamente, em altas doses, pode causar efeitos indesejáveis, como anemia por hemólise extravascular e aumento de bilirrubina no soro, os quais são reversíveis quando cessada a administração do fármaco (Bean 1992, Takahashi et al. 1998, Hosoya et al. 2001). Assim, sugere-se que a presença de bilirrubina na urina signifique a hemólise seja causada pela ribavirina e não necessariamente por uma lesão hepática. Da mesma forma aconteceu no décimo quinto dia de tratamento, houve um aumento da quantidade de bilirrubina na urina em todos os grupos, sendo que o G5 foi o que apresentou a maior dosagem de bilirrubina na urina. Outra hipótese para estes achados seriam indícios de uma sobrecarga do sistema hepatobiliar destes cães, na dose e intervalo entre doses da ribavirina utilizada na pesquisa. No entanto, nenhuma das amostras de urina apresentou positividade para a presença de sais biliares, o que diminui as chances que seja uma alteração no sistema hepatobiliar.

\section{CONCLUSÃO}

Conclui-se que a ribavirina na dose de $30 \mathrm{mg} / \mathrm{kg}$ administrada durante 15 dias consecutivos foi capaz de induzir anemia em cães naturalmente infectados com o vírus da cinomose. Pode-se verificar que a associação deste fármaco com a prednisona piorou o quadro de anemia nos cães. Sugere-se que novos estudos sejam realizados com o objetivo de identificar e classificar o tipo de anemia produzida por esses medicamentos em cães para facilitar a sua utilização na rotina clínica.

Agradecimentos.- Aos professores e residentes do Departamento de Higiene Veterinária e Saúde Pública, FMVZ, Unesp-Botucatu, SP. Ao Conselho Nacional de Desenvolvimento Científico e Tecnológico (CNPq). À Coordenação de Aperfeiçoamento de Pessoal de Nível Superior (CAPES), pela concessão de bolsa de doutorado.

\section{REFERÊNCIAS}

Ali B.H. 2001. Dimethyl sulfoxide: recent pharmalogical and toxicological research. Vet. Hum. Toxicol. 43:228-231.

Amaral H.A. 2007. Detecção do vírus da cinomose pela técnica de RT-PCR em cães com sintomatologia neurológica. Tese de Doutorado, Programa de Pós-Graduação em Clínica Veterinária, Universidade de São Paulo, São Paulo, SP.

Bean B. 1992. Antiviral therapy: current concepts and practices. Clin. Microbiol. Rev. 5:146-182.

Böhm M., Herrtage M.E., Weir A., Hasted A.M. \& Maxwell N.S. 2004. Serum antibody titers to canine parvovirus, adenovirus and distemper virus in dog in the UK wich had not been vaccinated for at least three years. Vet. Rec. 154:457-463.

Brayton C.F. 1986. Dimethyl sulfoxide (DMSO): a review. Cornell Vet. 76:61-90.

Dewey C.W. 2006. Neurologia de Cães e Gatos: guia prático. 2ª ed. Roca, São Paulo. 352p.

Elia G., Belloli C., Cirone F., Lucente M.S., Caruso M., Martella V., Decaro N., Buonavoglia C. \& Ormas P. 2008. In vitro efficacy of ribavirin against canine distemper virus. Antiviral Res. 77:108-13.

Greene C.E. \& Appel M.J. 2006. Canine distemper, p.25-41. In: Greene C.E. (Eds), Infectious Disease of the Dog and Cat. W.B. Saunders, Philadelphia.

Hayden F.G. \& Douglas R.G. Jr 1990. Antiviral agents, p.370-393. In: Mandell G.L., Douglas Jr R.G. \& Bennett J.E. (Eds), Principles and Pratice of Infectious Disease. Churchill Livingestone, New York. 
Headley S.A. \& Graça D.L. 2000. Canine distemper: Epidemiological findings of 250 cases. Braz. J. Vet. Res. Anim. Sci. 37(2):136-140.

Hosoya M., Shigeta S., Mori S., Tomoda A., Shiraishi S., Miike T. \& Suzuki H. 2001. High-dose intravenous ribavirin therapy for subacute sclerosing panencephalitis. Antimicrob. Agents Chemother. 45:943-945.

Józwik A. \& Frymus T. 2005. Comparison of the immunofluorescence assay with RT-PCR and Nested PCR in the diagnosis of canine distemper. Vet. Res. Commun. 29:347-359.

Kishioka T., Iida C., Fujii K., Nagae R., Onishi Y., Ichi I. \& Kojo S. 2007. Effect of dimethyl sulphoxide on oxidative stress, activation of mitogen actived protein kinase and necrosis caused by thioacetamide in the rat liver. Eur. J. Pharmacol. 564:190-195.

Lin C., Yeh L., Luu T., Lourenco D. \& Lau J.Y.N. 2003. Pharmacokinetics and metabolism of [14C] ribavirin in rats and Cynomologus monkeys. Antimicrob. Agents Chemother. 47:1395-1398.

Lind R.C., Begay C.K. \& Gandolfi J. 2000. Hepatoprotection by Dimethyl Sulfoxide. Toxicol. Appl. Pharmacol. 166:145-150.

Mangia S.H. 2008. Tratamento experimental de cães naturalmente infectados com o vírus da cinomose na fase neurológica com o uso da ribavirina e dimetil-sulfóxido (DMSO). Dissertação de Mestrado, Faculdade de Medicina Veterinária e Zootecnia, Universidade Estadual Paulista, Botucatu, SP. 152p.

Mangia S.H., Perrotti I.B.M., Martinho A.P.V. \& Paes A.C. 2011. Tratamento de cão com encefalite aguda pela cinomose. Anais 5 o Neurovet - Simpósio de Neurologia Veterinária, Florianópolis, SC, p.10. (Resumo)

Paes A.C. 1999. Estudo da potencialização da ação terapêutica da isoniazida pelo dimetil-sulfóxido (DMSO) no tratamento de hamsters (Mesocricetus auratus) experimentalmente infectados com Mycobacterium bovis (Cepa AN5). Tese de Doutorado, Faculdade de Medicina Veterinária e Zootecnia, Universidade de São Paulo, São Paulo, SP. 183p.
Papich M.G., Heit M.C. \& Riviere J.E. 2003. Fármacos antifúngicos e antivirais, p.767-790. In: Adams H.R. (Ed.), Farmacologia e Terapêutica em Veterinária. 8 ${ }^{\underline{a}}$ ed. Guanabara Koogan, Rio de Janeiro.

Silva L.H.Q., Morinishi C.K. \& Nunes C.M. 2004. Diagnóstico diferencial entre raiva e a cinomose em amostras de cérebro de cães examinadas no período de 1998 a 2001 na região de Araçatuba, SP, Brasil. Arqs Inst. Biológico, São Paulo, 71:317-321.

Sorrells S.F. \& Sapolsky R.M. 2007. An inflammatory review of glucocorticoid actions in the CNS. Brain Behav. Immun. 21:259-272.

Summers B.A. \& Appel M.J. 1994. Aspects of canine distemper virus and measles virus encephalomyelitis. Neuropathol. Appl. Neurobiol. 20:525534.

Sung H., Chang M. \& Saab S. 2011. Management of hepatitis C antiviral therapy adverse effects. Curr. Hepatitis Rep. 10:33-40.

Takahashi T., Hosoya M., Kimura K., Ohno K., Mori S., Takahashi K. \& Shigeta S. 1998. The cooperative effect of interferon- $\alpha$ and ribavirin on subacute sclerosing panencephalitis (SSPE) virus infections, in vitro and in vivo. Antiviral Res. 37:29-35.

Vandevelde M. \& Zurbriggen A. 2005. Demyelination in canine distemper virus infection: a review. Acta Neuropathol. 109:56-68.

West R.T., Garza L.A., Winchester W.R. \& Walmsley J.A. 1994. Conformation, hydrogen bonding and aggregate formation of guanosine $5^{\prime}$-monophosphate and guanosine in dimetylsulfoxide. Nucleic Acids Res. 22:5128-5134.

Wu J.Z., Larson G., Walker H., Shim J.H. \& Hong Z. 2005. Phosphorylation of ribavirin and viramidine by adenosine kinase and cytosolic 5'-Nucleotidase II: implications for ribavirin metabolism in erythrocytes. Antimicrob. Agents Chemother. 49:2164-2171. 